\title{
Study about the Sensitivity Analysis under Changing Scenario of Climate on Rice Crop for Faizabad Region of Uttar Pradesh, India
}

\author{
Sachin Kumar Shukla ${ }^{1}$, A.N. Mishra ${ }^{1}$, S.R. Mishra ${ }^{1}$, A.K. Singh ${ }^{1}$, \\ Sarvesh Baranwal ${ }^{1 *}$, S.K. Sharma ${ }^{1}$ and Kanhaiya Lal ${ }^{2}$ \\ ${ }^{1}$ Department of Agricultural Meteorology, Narendra Deva University of Agriculture and \\ Technology, Kumarganj, Faizabad, India \\ ${ }^{2}$ Department of Genetics and Plant Breeding, Chandra Shekhar Azad University of \\ Agriculture \& Technology, Kanpur-208002, Uttar Pradesh, India \\ *Corresponding author
}

\section{Keywords}

Sensitivity analysis,

Climate,

Rice crop,

Faizabad region

Article Info

Accepted:

10 April 2019

Available Online:

10 May 2019

\section{A B S T R A C T}

A field experiment of rice crop was conducted during Kharif season 2016 at Agrometeorological Research Farm of N.D.U.A\&T, of Kumarganj, Faizabad. The experiment was conducted in Randomized Block Design. The treatment comprised of three dates of Transplanting viz. 5th July (D1); 15th July (D2) and 25th July (D3) with three varieties viz. NDR-80 (V1); Pant Dhan-4 (V2) and Swarna (V3). In this study, DSSAT-CERES model was used to assess the impact of temperature on productivity of crop. Possible changes in temperature and solar radiation are expected to significantly impact the crop growth and yields. In this study, CERES rice model was used to assess the impact of temperature and solar radiation on physiology and productivity of rice crop at Faizabad region, Uttar Pradesh. The simulation of anthesis days, maturity days, grain yield and straw yield were carried out for the range of temperature (maximum and minimum both) $0.5^{\circ} \mathrm{C}$ and $+1.5^{\circ} \mathrm{C}$ with an interval of $0.5^{\circ} \mathrm{C}$ temperature from normal, alone or in combination with solar radiation $\pm 0.5, \pm 1$ and $\pm 1.5 \mathrm{MJ}$ m- 2 day- 1 while keeping the other climate variables constant. Anthesis days and maturity days reduced with increasing temperature. At increase of $1.5^{\circ} \mathrm{C}$ temperature, anthesis and maturity occurred 10 days and 11 days earlier from normal, respectively. Grain yield decreased and straw yield increased concurrently with an increase in temperature by $1.5^{\circ} \mathrm{C}$ and an increase in solar radiation (up to $1.5 \mathrm{MJ} \mathrm{m}-2$ day-1) in comparison with the normal conditions. It is inferred that increasing temperature and decreasing solar radiation hampers the crop phenology and the productivity in Faizabad region.

\section{Introduction}

Crop growth is an extremely complex phenomenon with complicated interactions of soil, plant and weather conditions. Climate changes have a great impact on agricultural production. The impact of weather variables on the entire crop growth period can be best represented by crop-weather models which facilitate the relationship between weather, soil, climate and crop yield. Crop growth simulation model can be used to evaluate key interactions quickly and identify traits with the greatest impact on yield potential and for assessing the relationships between crop productivity and environmental factors 
(Aggarwal et al., 1997). Crop growth simulation models are quantitative tool based on scientific knowledge that can evaluate the effect of climatic, edaphic, hydrological and agronomic factors on crop growth and yield. Boote et al (1996). India ranked first in area and second in production of rice in the world. The productivity of rice is largely affected by a set of weather variables among which solar radiation and temperature play a significant role. Agrometeorological models are defined as the product of two or more weather factors each representing functioning between yield and weather. These models do not require hypothesis of the plant and environment process. Thus the input requirement is less stringent but the output information is more dependent on the input data. The crop duration under different dates of transplanting are greatly influenced by temperature and may be estimated by accumulated heat units (Gouri et al., 2005). Several studies have shown that the total drymatter (TDM) produced by a crop cultivar is directly proportional to the amount of photosynthetically active radiation (PAR) intercepted by it. The quantum of intercepted PAR depends on life-duration of the cultivar from ground shading to physiological maturity and its leaf-architecture and the temporal march of solar radiation regime in the crop period. The ground-shading stage is a physical and not a physiological one. Time from sowing to ground shading stage is governed by initial population density and temperature. For a given location and season, the duration from ground average to physiological maturity will be varietaldependant. The beneficial effect of $\mathrm{CO}_{2}$ rise on growth and yield of crops is nullified by the rising temperature, Basically competition between the two abiotic elements only decide the impact on growth and yield of crops, especially in irrigated environments. Under rainfed and water limited environments, precipitation will also be a deciding factor along with temperature and carbon dioxide concentration. Agricultural productivity in majorly affected by climate change in two ways: one, directly, due to changes in temperature, precipitation or $\mathrm{CO}_{2}$ levels and two, indirectly, through changes in soil health (physical, chemical and biological), distribution and frequency of infestation by pests, insects, diseases or weeds. The main goal of a crop simulation model is to estimate crop production, resource use and environmental impact as a function of local weather and soil conditions and crop management (Hoogenboom, 2000). In India, substantial work has been done in recent decades aimed at understanding the nature and magnitude of change in yield of different crops using the crop simulation model and remote sensing technique (Mall et al., 2006; Aggarwal et al., 2008; Patel et al., 2010; Singh et al., 2010; Kumar et al., 2010)

\section{Materials and Methods}

The present study was carried out taking into account the anticipated regional climatic changes for Faizabad region of Uttar Pradesh. The climate of Faizabad region has a subtropical, controlled by south-west monsoon, characterized by a moderate to extreme condition. The experiment was conducted with Randomized block design and replicated four times with nine treatment combinations consisted of three dates of transplanting viz., 5th July (D1), 15th July (D2) and 25th July (D3) with three varieties viz., NDR-80 (V1); Pant Dhan-4 (V2) and Swarna (V3). The package and practices for cultivation was followed as per the recommendation of Crop parameters such as phenology, LAI, harvest index, straw yield and test weight were used for calibration of the DSSAT 4.6 model. The genetic coefficients of rice were estimated by repeated interactions until a close match between simulated and observed phenology 
and yield was obtained in respective treatments. In this paper we study about solar radiation and temperature effect on quantitative value of grain yield so here we are not mention the genetic coefficient.

\section{Results and Discussion}

Sensitivity analysis of rice to ambient temperature under optimal conditions

Data pertaining to sensitivity analysis of Rice to ambient temperature have been presented in Table 1 and 2. It is evident from the table that the simulated grain yield increased with successive increase of ambient temperature by $0.5^{\circ} \mathrm{C}$ over normal temperature as well as simulated grain yield are decreased with successive decrease ambient temperature of rice cultivar. Consequently, higher percent change from base yield of $4063 \mathrm{~kg} \mathrm{ha}^{-1}$ change $(13.2 \%)$ was recorded with increase of ambient temperature by $1.5^{0} \mathrm{C}$ over normal temperature obtained during the experimental crop period. It is evident from the table that the simulated grain yield increase from base yield with successive increase of the ambient temperature by $0.5^{0} \mathrm{C}, 1{ }^{0} \mathrm{C}$ and $1.5^{\circ} \mathrm{C}$ over cropping season normal, while successive decrease of temperature by $0.5^{\circ} \mathrm{C}, 1^{\circ} \mathrm{C}$ and $1.5^{\circ} \mathrm{C}$ over normal decrease the grain yield of
Rice. Consequently maximum percent change from base yield (12.2\%) was recorded with increase of temperature by $1.5^{\circ} \mathrm{C}$ over normal, whereas $0.5^{\circ} \mathrm{C}$ decrease in temperature reduced the yield to $-8 \%$ only. Comparative study of $1^{0} \mathrm{C}$ successive increase in temperature on yield of Rice revealed that successive temperature though increases the yield, but due to $1^{0} \mathrm{C}$ successive decrease in temperature yield decrease. Data pertaining to sensitivity analysis of rice to ambient temperature also a well depicted in chart figure 1 and 2.

\section{Sensitivity analysis of Rice to solar} radiation under optimal conditions

Data pertaining to sensitivity analysis of rice to solar radiation ( $\mathrm{MJ} \mathrm{m}{ }^{-2}$ day $^{-1}$ ) have been presented in Table 3 and 4. It is evident from the table that the simulated grain yield increased with successive increase of solar radiation by $0.5^{0} \mathrm{C}$ over normal solar radiation as well as simulated grain yield are decreased with successive decrease solar radiation of rice cultivar. Consequently, higher percent change from base yield of $4063 \mathrm{~kg} \mathrm{ha}^{-1}$ change $(13.2 \%)$ was recorded with increase of solar radiation by $1.5^{\circ} \mathrm{C}$ over solar radiation obtained during the experimental crop period.

Table.1 Sensitivity analysis of ambient temperature for simulate of grain yield

\begin{tabular}{|c|c|c|c|}
\hline $\begin{array}{c}\text { Cultivar } \\
\begin{array}{c}\text { Ambient } \\
\text { temperature }\end{array}\end{array}$ & $\begin{array}{c}\text { NDR-80 } \\
\text { \% change from } \\
\text { base } \mathbf{( 4 0 6 3 )} \text { yield }\end{array}$ & $\begin{array}{c}\text { Pant Dhan-4 } \\
\text { \% change from } \\
\text { base (4063) yield }\end{array}$ & $\begin{array}{c}\text { Swarna } \\
\text { change from } \\
\text { base (4063) yield }\end{array}$ \\
\hline $\mathbf{0 . 5}$ & +9 & +3.3 & +2.4 \\
\hline $\mathbf{1}$ & +10.8 & +5.1 & +4.1 \\
\hline $\mathbf{1 . 5}$ & +12.2 & +7.4 & +4.6 \\
\hline $\mathbf{- 0 . 5}$ & -8.0 & -1.2 & -0.6 \\
\hline $\mathbf{- 1}$ & -4.6 & -2.8 & -2.8 \\
\hline $\mathbf{- 1 . 5}$ & -3.4 & -3.3 & -4.1 \\
\hline
\end{tabular}


Table.2 Sensitivity analysis of ambient temperature for simulate of grain yield

\begin{tabular}{|c|c|c|c|}
\hline $\begin{array}{c}\text { Cultivar } \\
\begin{array}{c}\text { Ambient temperature } \\
\mathbf{0} \text { C }\end{array}\end{array}$ & $\begin{array}{c}\text { NDR-80 } \\
\text { Modified Simulation } \\
\text { grain yield kg/ha }\end{array}$ & $\begin{array}{c}\text { Pant Dhan-4 } \\
\text { Modified Simulation } \\
\text { grain yield kg/ha }\end{array}$ & $\begin{array}{c}\text { Sodified Simulation } \\
\text { grain yield kg/ha }\end{array}$ \\
\hline $\mathbf{0 . 5}$ & 4427 & 4804 & 4323 \\
\hline $\mathbf{1}$ & 4500 & 4890 & 4398 \\
\hline $\mathbf{1 . 5}$ & 4557 & 4994 & 4416 \\
\hline $\mathbf{- 0 . 5}$ & 4390 & 4597 & 4197 \\
\hline $\mathbf{- 1}$ & 4250 & 4521 & 4103 \\
\hline $\mathbf{- 1 . 5}$ & 4200 & 4498 & 4051 \\
\hline
\end{tabular}

Table.3 Sensitivity analysis of solar radiation for simulate grain yield

\begin{tabular}{|c|c|c|c|}
\hline Cultivar & NDR-80 & Pant Dhan-4 & Swarna \\
\hline $\begin{array}{c}\text { Solar radiation } \\
\mathrm{Mj} / \mathrm{m}^{2} / \text { day }\end{array}$ & $\begin{array}{c}\% \text { change from base } \\
(4063) \text { yield }\end{array}$ & $\begin{array}{l}\text { \% change from base } \\
(\mathbf{4 0 6 3 )} \text { yield }\end{array}$ & $\begin{array}{c}\% \text { change from base } \\
(4063) \text { yield }\end{array}$ \\
\hline 0.5 & +6.5 & +9.4 & +4 \\
\hline 1 & +10.7 & +7.1 & +5.4 \\
\hline 1.5 & +13.2 & +8.9 & +4.1 \\
\hline-0.5 & -0.8 & -2.0 & -0.5 \\
\hline-1 & -2.6 & -2.6 & -2.2 \\
\hline-1.5 & -4.5 & -1.1 & -3.2 \\
\hline
\end{tabular}

Table.4 Sensitivity analysis of solar radiation for simulate grain yield

\begin{tabular}{|c|c|c|c|}
\hline Cultivar & NDR-80 & Pant Dhan-4 & Swarna \\
\hline $\begin{array}{c}\text { Solar radiation } \\
\mathbf{M j} / \mathbf{m}^{2} / \text { day }\end{array}$ & $\begin{array}{c}\text { Modified } \\
\text { Simulation grain } \\
\text { yield kg/ha }\end{array}$ & $\begin{array}{c}\text { Modified } \\
\text { Simulation grain } \\
\text { yield kg/ha }\end{array}$ & $\begin{array}{c}\text { Modified } \\
\text { Simulation grain } \\
\text { yield kg/ha }\end{array}$ \\
\hline $\mathbf{0 . 5}$ & 4329 & 5089 & 4420 \\
\hline $\mathbf{1}$ & 4497 & 4980 & 4453 \\
\hline $\mathbf{1 . 5}$ & 4600 & 5068 & 4395 \\
\hline $\mathbf{- 0 . 5}$ & 4031 & 4557 & 4202 \\
\hline $\mathbf{- 1}$ & 3956 & 4532 & 4130 \\
\hline $\mathbf{- 1 . 5}$ & 3879 & 4601 & 4087 \\
\hline
\end{tabular}


Fig.1

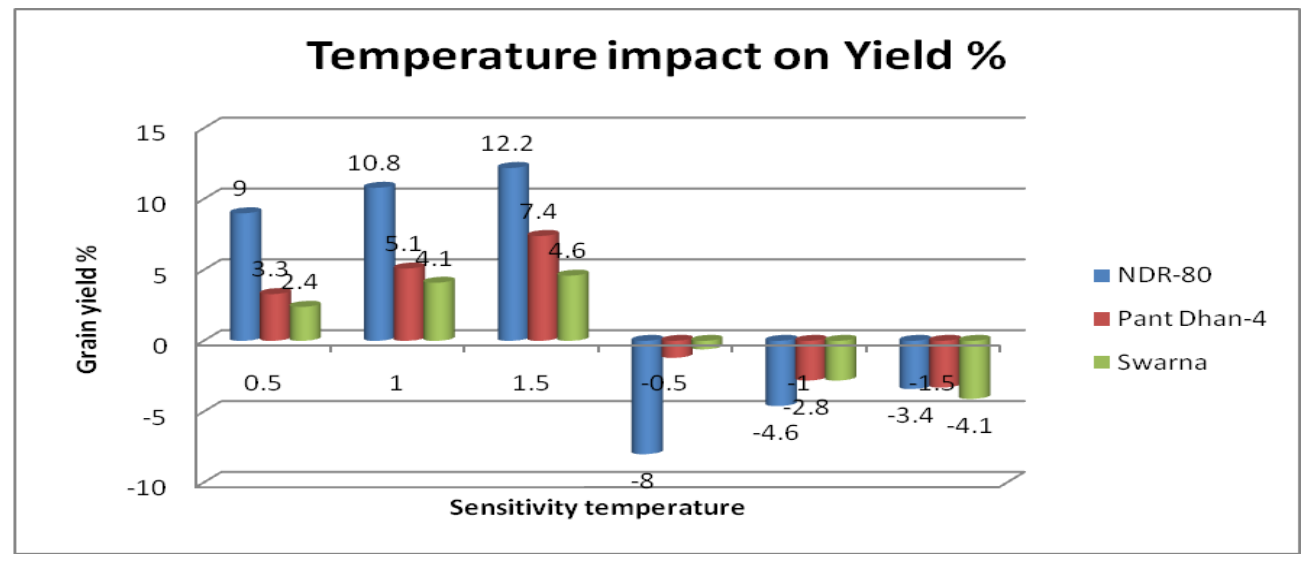

Fig.2

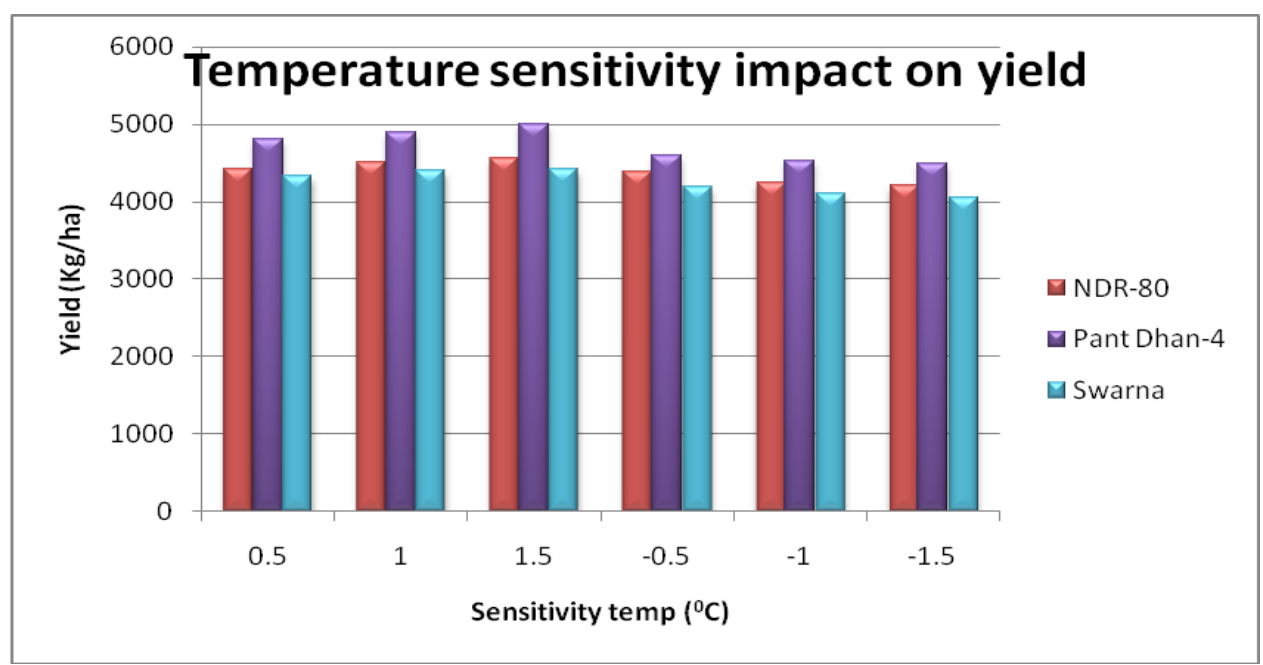

Fig.3

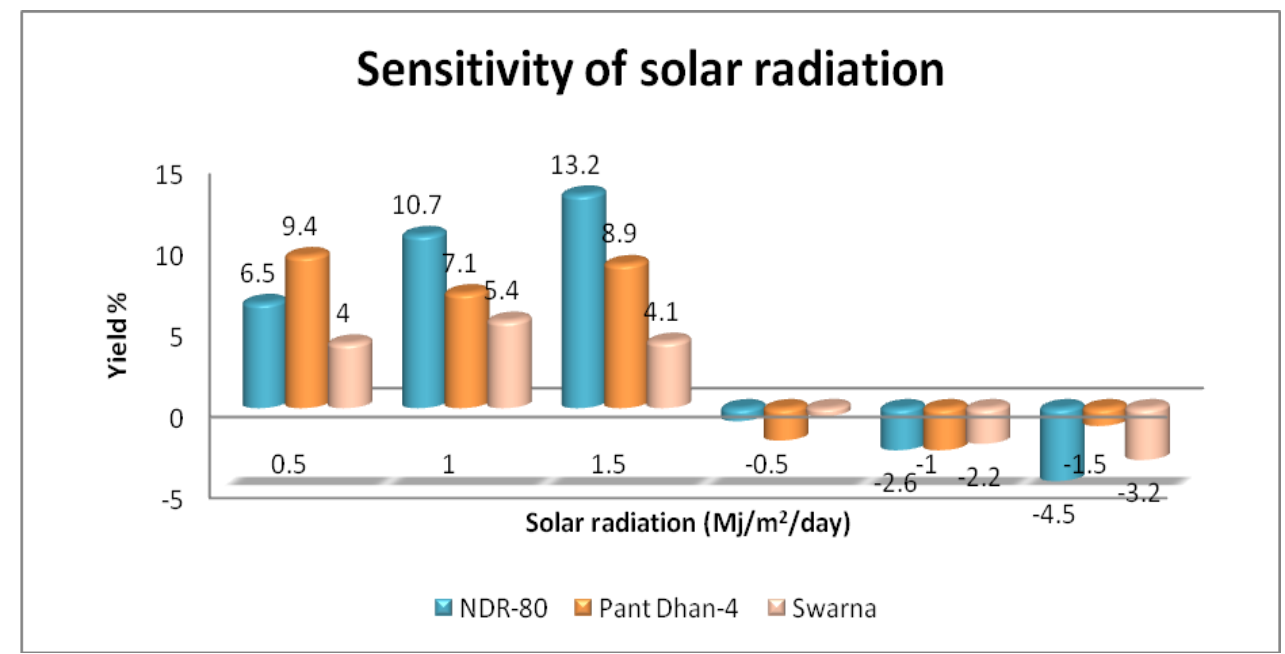


Fig.4

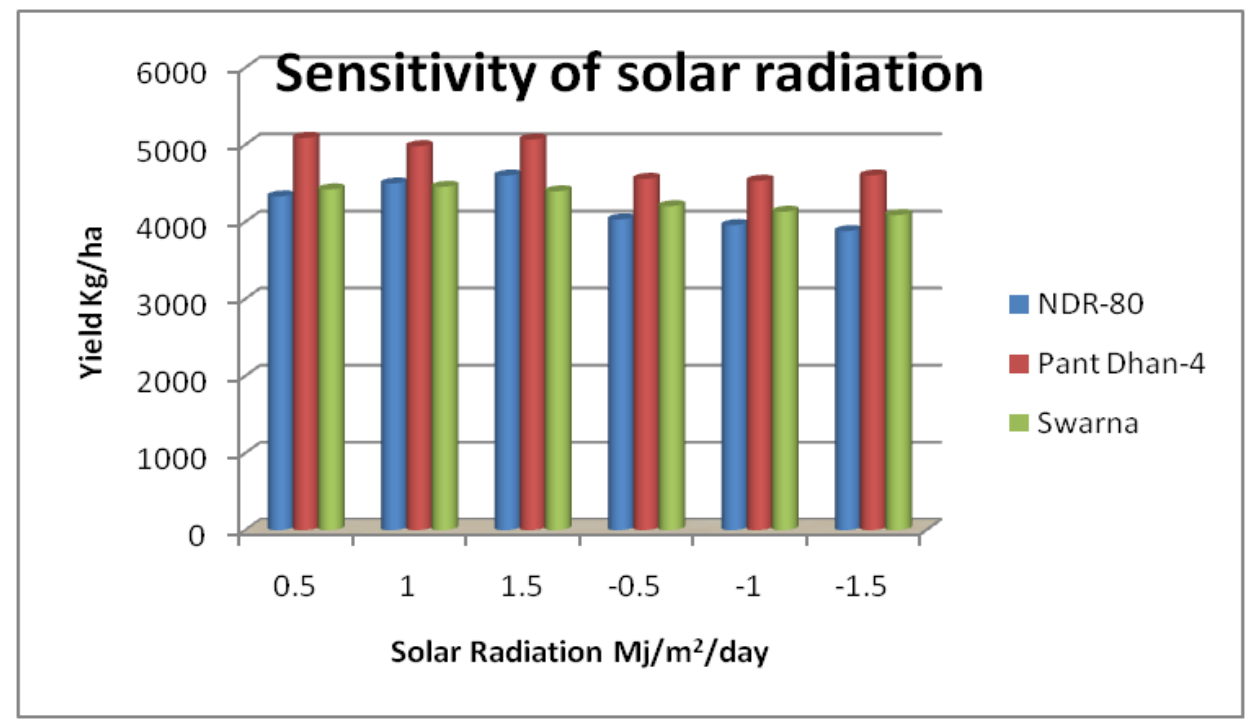

It is evident from the table that the simulated grain yield increased from base yield with successive increase of the solar radiation by $+0.5,+1,+1.5$ MJ m${ }^{-2}$ day $^{-1}$ over cropping season normal, while successive decrease of solar radiation by $+0.5,+1,+1.5 \mathrm{MJ} \mathrm{m}^{-2}$ day $^{-1}$ over normal decreased the grain yield of rice considerably. Consequently maximum $\%$ of yield increase change from base yield was recorded $(13.2 \%)$ with increase the solar radiation by $+0.5,+1,+1.5 \mathrm{MJ} \mathrm{m}^{-2}$ day $^{-1}$ over normal. Decrease of solar radiation by +0.5 , $+1,+1.5 \mathrm{MJ} \mathrm{m}^{-2}$ day $^{-1}$ decrease the yield by $4.5 \%$ only from base yield. This showed that solar radiation was most sensitive parameters for rice production as compare to temperature because yield increase/decrease on unit basis was lower for temperature as compare to solar radiation. Data pertaining to sensitivity analysis of rice to ambient temperature also a well depicted in chart figure $3 \& 4$.

\section{References}

Aggarwal, P.K. (2008). Global climate change and Indian agriculture. Indian J. Agric. Sci., 78: 911-919.

Aggarwal, P.K., Kropff, M.J., Cassman, K.G. and Berge, H.F.M. (1997). Simulating genotypic strategies for increasing rice yield potential in irrigated, tropical environments. Field Crops Res., 51:517.

Boote, K.J., Jones, J.W. and Pickering, N.B. (1996). Potential use and limitations of crop models. Agron. J., 88: 70416.

Gouri, V., Reddy, D.R., Rao, S.B.S.N. and Rao, A.Y. (2005). Thermal requirement of rabi groundnut in southern Telungana zone of Andhra Pradesh. J. Agrometeorol., 7: 90-94.

Hoogenboom, G. (2000). Contribution of agro meteorology to the simulation of crop production and its applications. Agric. Forest Meteorol., 103(1): 137-157.

Kumar Arvind, Singh, K.K., Balasubramanyan, R., Baxla, A.K., Tripathi, P. and Mishra, B.N. (2010). Validation of CERES-Maize model for growth, yield attributes and yield of kharif maize for NEPZ of eastern U.P. J. Agrometeorology. 12(1): 118120.

Mall, R.K., Singh, Ranjeet, Gupta, Akhilesh, Srinivasan, G. and Rathore, L.S. (2006). Impact of Climate Change on Indian Agriculture: A Review. Climatic Change, 78: 445478. 
Patel, H.R., Patel, G.G., Shroff, J.C., Pandey, V., Shekh, A.M., Vadodaria, R.P. and Bhatt, B.K. (2010). Calibration and validation of CERES-Wheat model for wheat in middle Gujarat region. J. Agrometeorology. 12(1): 114-117.
Singh, Raj, Singh, Diwan, Chander Shekhar and Mani, J.K. (2010). Evaluation of SOYGRO model for Soybean crop under Hisar conditions. J. Agrometeorology. 12(1): 121122.

\section{How to cite this article:}

Sachin Kumar Shukla, A.N. Mishra, S.R. Mishra, A.K. Singh, Sarvesh Baranwal, S.K. Sharma and Kanhaiya Lal. 2019. Study about the Sensitivity Analysis under Changing Scenario of Climate on Rice Crop for Faizabad Region of Uttar Pradesh. Int.J.Curr.Microbiol.App.Sci. 8(05): 943-949. doi: https://doi.org/10.20546/ijcmas.2019.805.109 